\title{
1 Long- and short-range bimodal signals mediate mate 2 location and recognition in yellow fever mosquitoes
}

4 Elton Ko*, Chiara Lier, Adam J. Blake, Stephen Takács, Gerhard Gries

6 Department of Biological Sciences, Simon Fraser University, 8888 University Drive, Burnaby,

7 British Columbia V5A 1S6, Canada

8

$9 \quad *$ Correspondence: eltonk@sfu.ca 


\section{Abstract}

27 As recently reported, light flashes of incident sunlight reflecting off the wings of in-flight

28 dipterans serve as mate recognition signals. Mate location and mate selection behavior in the

29 yellow fever mosquito, Aedes aegypti, take place in mating swarms but the mechanisms

30 underlying swarm formation and long-range detection of females by males remain largely

31 unexplored. Here we show that swarm formation and mate recognition are mediated, in part, by

32 light flash signals and wingbeat sound signals that operate at long and short range, respectively.

33 To test for range-dependent effects of these signals, we presented 'mating swarms' in form of

34 two paired 8-LED assemblies that were fitted with micro-speakers and placed either well

35 separated in a large space or side-by-side in a small space. In the large but not the small space,

36 the LED assembly flashing light at the wingbeat frequency of females $(665 \mathrm{~Hz})$, and emitting

37 their wingbeat sound $(665 \mathrm{~Hz})$, attracted and prompted 5.8-times more alightings by males than

38 the LED assembly emitting constant light and wingbeat sound. In the small space, the LED

39 assembly flashing light and emitting wingbeat sound induced 5.0-times more alightings by males

40 than the LED assembly flashing light without wingbeat sound. Females responded to light flash

41 signals of males, but males failed to respond to the synthetic female pheromone component

42 ketoisophorone added to the bimodal complex of light and sound signals. The attractiveness of

43 light flash signals to males increased with increasing numbers of signals but did not vary

44 according to their wavelengths (UV or blue). As predicted by the sensory drive theory, light

45 flashes had no signal function for crepuscular house mosquitoes, Culex pipiens. 


\section{INTRODUCTION}

49 Searching for a blood meal, female mosquitoes exploit multiple vertebrate host cues including

$50 \mathrm{CO}_{2}$, body odor, moisture, as well as visual and heat contrast. ${ }^{1}$ To locate a host, female

51 mosquitoes are guided by these chemical and physical cues in sequential and interactive

52 processes. ${ }^{2,3,4}$ Exhaled in the breath of a potential host, $\mathrm{CO}_{2}$ context-dependently ${ }^{5}$ promotes host-

53 seeking, ${ }^{6,7}$ elicits upwind flight toward the $\mathrm{CO}_{2}$ source, ${ }^{8,9}$ and enhances mosquito attraction to

54 warmth. ${ }^{10,11}$ In addition to exhaled $\mathrm{CO}_{2}$, breath volatiles and numerous odorants emanating from

55 bacteria on vertebrate $\operatorname{skin}^{12-14}$ guide host-foraging mosquitoes. The relative importance of host

56 cues depends on the spatial scale, with some cues (thermal, skin odours, visual, moisture) being

57 most important at close range. ${ }^{4,15,16,17}$

58 Nectar-foraging mosquitoes also exploit multimodal cues to locate floral resources. ${ }^{18}$

59 Females of the yellow fever mosquito, Ae. Aegypti, and the Northern house mosquito, Culex

60 pipiens, respond more strongly to a cue complex of tansy, Tanacetum vulgare, inflorescences,

61 consisting of $\mathrm{CO}_{2}$, olfactory and visual cues, than to inflorescence odor alone. ${ }^{18}$ During floral

62 foraging, floral odor likely acts as a long-range attractant, whereas visual cues are utilized at

63 closer ranges.

64 While the multimodal sensory cues that guide foraging mosquitoes to host and nectar

65 resources have been intensely studied, the mechanisms underlying mate location and recognition

66 in mosquitoes are not fully understood. Many mosquito species form 'mating swarms'

67 dominated by males ${ }^{19}$ that independently respond to 'swarm marker' objects in the

68 environment $^{19}$, such as trees, corn stalks, telephone poles ${ }^{20}$ or just black cards. ${ }^{21}$ In Ae. aegypti,

69 the vertebrate host itself serves as the swarm marker. ${ }^{22}$ Swarming behavior exposes mosquitoes

70 to predation ${ }^{23}$ and is energetically costly, ${ }^{24}$ but it expedites mate location which is challenging

71 for species with widespread larval habitats. ${ }^{19}$

72 In the context of swarming, mosquitoes respond to acoustic, visual and pheromonal signals

73 or cues from conspecifics. ${ }^{25-27}$ As shown for several species, swarming males recognize the

74 wingbeat frequency of conspecific females that enter a swarm. ${ }^{25,28,29}$ The sound-receiving

75 Johnston's organ in the males' antennae is attuned to the females' wingbeat frequencies ${ }^{25,29}$

76 which are attractive to males. ${ }^{30}$ After successful coupling with the female, the male-female pair

77 leaves the swarm to mate. ${ }^{31}$ In Ae. aegypti, courtship precedes coupling and entails harmonic

78 convergence of both male and female wingbeat frequencies. ${ }^{32}$ Analogous behaviour has been 
79 reported in the elephant mosquito, Toxorhynchites brevipalpis, ${ }^{33}$ the southern house mosquito,

80 Culex quinquefasciatus, ${ }^{34}$ and the African malaria mosquito, Anopheles gambiae. ${ }^{35}$

81 Males typically detect the wingbeat sound of females only at close range, ${ }^{36}$ indicating that

82 physical mate location cues other than sound function at a longer range, as recently shown for

83 several dipterans, including mosquitoes. ${ }^{27,37}$ Males of the common green bottle fly, Lucilia

84 sericata, distinguish between the rates of light flashes reflected off the wings of in-flight female

85 and male flies, and are most strongly attracted to flash frequencies $(178 \mathrm{~Hz})$ characteristic of

86 young females. ${ }^{37}$ Similarly, 8-LED 'mating swarm' mimics of Ae. aegypti flashing white or blue

87 light at the wing beat frequency of females $(665 \mathrm{~Hz})$ attract conspecific males. ${ }^{27}$ As thin-film

88 reflectors, ${ }^{37,38}$ sun-exposed mosquito wings also reflect UV wavelengths which could be even

89 more attractive than the previously tested white or blue lights (see above). As mosquitoes can

90 sense UV light ${ }^{39}$ and behaviorally respond to it when they seek floral nectar ${ }^{18}$ or oviposition

91 sites, ${ }^{40}$ it is conceivable that UV light reflections play a role in the context of mate recognition.

92 Volatile or contact sex pheromones have been hypothesized to contribute to mate location and

93 recognition in mosquitos ${ }^{41-43}$ but supportive evidence for such pheromones remains scant. ${ }^{26}$

94 Females of Ae. aegypti reportedly produce a 3-component sex pheromone blend comprising

95 2,6,6-trimethylcyclohex-2-ene-1,4-dione ('ketoisophorone'), 2,2,6-trimethylcyclohexane-1,4-

96 dione (the saturated analogue of ketoisophorone), and 1-(4-ethylphenyl) ethanone ('ethanone'). ${ }^{26}$

97 In laboratory but not field settings, ketoisophorone alone elicited swarming-like flight by males.

98 Both ketoisophorone and its saturated analogue prompted "excited flights" by females, whereas

99 ethanone attracted females. ${ }^{26}$

100 All the visual, acoustic or pheromonal mate location or recognition cues of mosquitoes

101 described above were studied focused invariably on a single sensory modality, discounting

102 possible interactions between cues and their potential function at spatially different scales.

103 Furthermore, specifics of light flash cues on mate attraction such as the number of mosquitoes in

104 a mating swarm generating these cues, or the most attractive wavelengths of these cues, have not

105 yet been experimentally tested. Conceivably, large mating swarms with many mosquitoes

106 'flashing lights' are more attractive than small ones. Conversely, one would predict that

107 mosquitoes swarming at dusk when light flash cues are less conspicuous and may not rely on

108 visual cues for mate location or recognition. 
Working with diurnal Ae. aegypti, we tested six hypotheses $(\mathrm{H}):(\mathrm{H} 1, \mathrm{H} 2)$ the attractiveness of a mating swarm (i.e., array of light-flashing LEDs) is dependent upon both swarm size (i.e.,

111 number of LEDs in array) and the spectral composition of wing flashes (i.e., light emitted by

112 LEDs); (H3) wingbeat light flashes and sound of Ae. aegypti females are long- and short-range

113 male attraction signals, respectively; (H4) swarm pheromone of Ae. aegypti females increases the

114 attractiveness of their wingbeat light flashes and sound; and (H5) wing beat light flashes of Ae.

115 aegypti males attract mate-seeking females. Working with $C$. pipiens as a model species for

116 nocturnal mosquitoes, we further tested the hypothesis (H6) that dusk-swarming C. pipiens do

117 not exploit wingbeat light flashes for mate attraction

\section{RESULTS}

H1: The attractiveness of a mating swarm (i.e., array of light-flashing LEDs) is dependent upon

121 swarm size (i.e., number of LEDs in array)

122 To determine the effect of swarm size (i.e., LED numbers in array) on swarm attractiveness, we 123 released groups $(\mathrm{n}=10)$ of 50 males into mesh cages for each experiment) and video recorded 124 their alighting responses (as a measure of attraction) on each of two LED arrays (Fig. 1B) that 125 differed in the number of LEDs flashing blue light (Fig. S4) at $665 \mathrm{~Hz}$ (the wing beat frequency 126 of females) (Table 1). When given a choice between a 1-LED array and an 8-LED array, males 127 alighted more often on the latter $(F=67.529, p<0.0001$; Fig. 2, Exp. 1). In contrast, 4- and 8128 LED arrays prompted similar numbers of alighting responses by males $(F=0.64, p=0.64$; Fig. 129 2, Exp. 2). However, 16-LED arrays received three times more alighting responses than 8-LED 130 arrays $(\mathrm{F}=22.63, \mathrm{p}=0.001$; Fig. 2, Exp. 3). These data in combination support the hypothesis 131 that swarm size affects its attractiveness to mate-seeking males.

H2: The attractiveness of a mating swarm (i.e., array of light-flashing LEDs) is dependent upon

134 the spectral composition of wing flashes (i.e., light emitted by LEDs)

135 To determine whether the attractiveness of mating swarms depends upon the wavelength of light 136 reflected off the wings of swarming mosquitoes, we offered groups $(n=10)$ of 50 males a choice 137 between two 8-LED arrays (Fig. 1B) flashing (665 Hz) either blue light (422 nm) or UV light 138 (360 nm) (Table 1; Fig. S4). Video-recordings revealed that males alighted similarly often on the 139 UV LED array and the blue LED array $(\mathrm{n}=10, \mathrm{~F}=3.84, \mathrm{p}=0.081$, Fig. 3, Exp. 4), suggesting 
the short wave spectral content of wing flashes does not modulate the attractiveness of mating swarms.

H3: Wingbeat light flashes and sound of Ae. aegypti females are long-and short-range male attraction signals, respectively

To determine whether wingbeat light flashes of females $(665 \mathrm{~Hz})$ are long-range male attraction signals, we ran an experiment of identical design in both small and large spatial settings (mesh cage, room; Fig. 1A,B,D,E), offering groups $(n=10)$ of 50 males a choice between two 8-LED arrays separated by $15 \mathrm{~cm}$ (mesh cage) or $164 \mathrm{~cm}$ (room) (Table 1). The LEDs of array 1 flashed blue light at $665 \mathrm{~Hz}$, whereas the LEDs of array 2 emitted constant blue light. Each LED in both arrays was coupled with an earbud speaker (Fig. 1G) broadcasting female wingbeat sound (665 $\mathrm{Hz}$ ). In the cage setting, where males are already near mating swarms (i.e., LED arrays) and can hear the wing beat sound, the type of visual stimulus (flashing or constant light) had no effect on alighting responses by males $(n=10, F=0.86, p=0.86$, Fig. 4, Exp. 5). Conversely, in the room setting, where males still needed to locate mating swarms (i.e., LED arrays), LED arrays flashing blue light prompted 5.8-times more alighting responses by males than LED arrays emitting constant blue light $(\mathrm{n}=10, \mathrm{~F}=30.43, \mathrm{p}=0.001$, Fig. 4, Exp. 6). The data of both experiments combined support the hypothesis that wingbeat light flashes of females attract males at longrange.

To confirm that wingbeat sound of females $(665 \mathrm{~Hz})$ is a short-range male attraction signal (see above), we offered groups $(\mathrm{n}=10)$ of 50 males in the mesh cage setting a choice between two 8-LED arrays fitted with earbud speakers that broadcasted either the females' wingbeat sound (array 1) or white noise (control stimulus; array 2) (Table1). The LEDs of both arrays flashed blue light $(665 \mathrm{~Hz})$. In this cage setting, where males are already near mating swarms (i.e., LED arrays) and can distinguish between arrays with or without wing beat sound, arrays with wing beat sound prompted 5-times more alighting responses by males $(\mathrm{n}=10 ; \mathrm{F}=19.87 ; \mathrm{p}$ $=0.001 ;$ Fig. 4 ; Exp. 7).

To ascertain that the white noise had no repellent effect on the males' responses in experiment 7, speakers of array 2 were kept silent in follow-up experiment 8 which otherwise was identical (Table 1). Similar to data obtained in experiment 7, arrays with wing beat sound prompted 4.9-times more alighting responses by males $(n=10, F=39.97, p=0.0001$; Fig. 4, 
171 Exp. 8). The data of both experiments combined support the hypothesis that the wingbeat sound

172 of females attracts males at close range.

173 To further investigate whether males can indeed distinguish between the wing beat sounds

174 of females and males and are attracted only to the sound of females, we offered groups $(\mathrm{n}=10)$

175 of 50 males a choice between two 8-LED arrays flashing blue light at $715 \mathrm{~Hz}$ (the wing flash

176 frequency of males), with earbud speakers of array 1 emitting male wing beat sound $(715 \mathrm{~Hz})$

177 and speakers of array 2 broadcasting white noise (Table 1). Fewer alighting responses by males

178 on arrays coupled with male wing beat sound $(n=10, F=5.49, p=0.043$; Fig. 5, Exp. 9)

179 indicate that males are put off by their own wingbeat sound, obviously distinguishing it from that

180 of females.

H4: Swarm pheromone of Ae. aegypti females increases the attractiveness of their wingbeat light

184 To test whether the swarm pheromone component ketoisophorone increases the attractiveness of 185 the females' wingbeat light flash and sound signals, we released groups of 50 males $(n=9)$ into a room and offered them a choice between two well-spaced 8-LED arrays each fitted with 8 earbud speakers (Fig. 1G, Table 1). All 16 LEDs flashed blue light (665 Hz) and all earbud speakers broadcasted corresponding wingbeat sound $(665 \mathrm{~Hz})$. The randomly assigned treatment males on arrays with or without pheromone $(n=9, F=0.076, p=0.79$; Fig. 6, Exp. 10), indicating no effect of female pheromone on mate-seeking males.

194 To determine whether wing beat light flashes of Ae. aegypti males $(715 \mathrm{~Hz})$ attract mate-seeking 195 females, we ran a small-space (cage) experiment, offering groups $(n=13)$ of 50 females a choice 196 between two 8-LED arrays separated by $15 \mathrm{~cm}$ (Table 1). All LEDs of array 1 emitted constant 197 white light (Fig. S4), whereas all LEDs of array 2 flashed white light at $715 \mathrm{~Hz}$. Video-

198 recordings revealed that females alighted more often on arrays with flashing lights than on arrays 199 with constant light $(\mathrm{n}=13, \mathrm{~F}=4.94, \mathrm{p}=0.046$, Fig. 7, Exp. 11). 
203 To determine whether dusk-swarming $C$. pipiens use wingbeat light flashes as mate attraction 204 cues, we ran three experiments (Exps. 12-14) in the mesh cage setting, one of which (Exp. 14) 205 under dim light (1 lux) (Table 1). In each experiment, we offered groups of 50 2- to 7-day-old $C$. 206 pipiens males a choice between two 8-LED arrays separated by $15 \mathrm{~cm}$. All LEDs of array 1 207 emitted constant white light (Fig. S4), whereas all LEDs of array 2 flashed white light at either $350 \mathrm{~Hz}(\operatorname{Exp} .12, \mathrm{n}=10)$ or $550 \mathrm{~Hz}(\operatorname{Exp} .13, \mathrm{n}=9$; Exp. 14, $\mathrm{n}=10)$, two previously reported wingbeat frequencies of female $C$. pipiens. ${ }^{34,44}$ In all three experiments, very few males alighted on arrays (Fig. S1), revealing no effect of light cues on male attraction, and not warranting

211 statistical analyses of data.

\section{DISCUSSION}

214 The wing light flash-guided mate location and recognition system of Ae. aegypti takes place in a 215 swarm context but otherwise resembles that of other dipterans. This remarkable mate recognition 216 system hinges upon the immense processing speed of dipteran photoreceptors ${ }^{45,46}$ and was only 217 recently discovered in the common green bottle fly, L. serricata. ${ }^{37}$ Ever since, the same type of 218 system has been shown to occur in other dipteran taxa, including house flies, Musca domestica, 219 black soldier flies, Hermetia illucens, and Ae. aegypti. ${ }^{27}$

220 The system in green bottle flies depends upon both the frequencies of light flashes caused by 221 moving wings being sex- and age-specific, and the ability of male bottle flies to recognize the 222 light flash frequency of young female flies that are prospective mates. ${ }^{37}$ A single LED flashing 223 white light at the wingbeat frequency of young females $(178 \mathrm{~Hz})$ is sufficient to attract and 224 prompt alighting responses by males. ${ }^{37}$ In Ae. aegypti, however, mate location typically takes 225 place in a swarm context, ${ }^{22,47}$ and a single light-flashing LED is not attractive to males or 226 females (Gries et al., unpubl.). To present a 'mating swarm' and to test its attractiveness to 227 males, we built assemblies of 8 LEDs (Fig. 1) and offered groups of males a choice between two 228 assemblies that emitted either constant light or light flashing at one of eight frequencies (430, $229480,500,545,665,800,950 \mathrm{~Hz}){ }^{27}$ In these experiments, males invariably alighted more often 230 on flashing-light LEDs than on constant-light LEDs (Fig. S2; adapted from ${ }^{27}$ ), suggesting that 231 mate-seeking males may respond to flashing lights of swarming males to locate swarms.

232 However, the effect of wingflash light signals on the responses of males in this previous study ${ }^{27}$ 
233 was tested in the absence of wingbeat sound and in a relatively small space. To reveal the effects

234 of light and sound signals [which are perceived at long and short $(<25 \mathrm{~cm})$ range, respectively]

235 at different spatial levels, we ran experiments in both a large setting $(2.25 \times 2.1 \times 2.4 \mathrm{~m}$ high $)$

236 and a small setting $(61 \times 61 \times 61 \mathrm{~cm})$. Our selection of the female (rather than the male)

237 wingbeat light flash and sound frequency (665 Hz each) as test stimuli for the response of males

238 was guided by four considerations: (1) even though females do not form mating swarms on their

239 own, multiple females may concurrently be present in a mating swarm sought after by males. For

240 example, in Anopheles stephensi mysorensis, as many as $23 \%$ of swarm mates were found to be

241 females; ${ }^{48}$ (2) males ought to be able to recognize females approaching a swarm, or flying well

242 apart within a swarm, at a distance greater than the hearing range for wingbeat sound (15-25

$243 \mathrm{~cm}) ;^{36}$ (3) light flash frequencies covering the range produced by females $(665 \mathrm{~Hz})$ and males

$244(715 \mathrm{~Hz})$ were both highly and almost equally attractive to males (Fig. S2); and (4) mate location

245 in Ae. aegypti may also occur in a context other than mating swarms. ${ }^{42,49}$

246 Our data show that flashing lights $(665 \mathrm{~Hz})$ are long-range signals that attract males to

247 mating swarms or to mates (Fig. 4). In a large-space setting, LED assemblies flashing light at

$248665 \mathrm{~Hz}$ and emitting wingbeat sound $(665 \mathrm{~Hz})$ prompted 5.8-times more alighting responses than

249 LED assemblies emitting constant light and wingbeat sound (665 Hz) (Fig. 4, Exp. 6).

250 Conversely, in a small space setting, when wingbeat sounds were present, flashing lights had no

251 apparent signal characteristics. Each of two LED assemblies producing either flashing or

252 constant light induced similar numbers of alightings by males (Fig. 4, Exp. 5).

253 Our data (Fig. 4, Exps. 7, 8) also confirm that the wingbeat sound of females is a close-range

254 signal to mate-seeking males. ${ }^{36,50,51}$ When offered a choice between two LED assemblies, both

255 flashing light $(665 \mathrm{~Hz})$ but only one emitting female wingbeat sound, males alighted 5.0- and

256 4.9-times more often on assemblies emitting female wingbeat sound than on assemblies that

257 emitted white noise or were silent (Fig. 4, Exps. 7, 8). Conversely, the wingbeat sound of males

258 (715 Hz) was off-putting to mate-seeking males (Fig. 5, Exp. 9), corroborating previous

259 conclusions that males distinguish between wingbeat sounds of females and males. ${ }^{25,52}$

260 The attractiveness of light flash mate location signals - tested in small-space bioassays in

261 the absence of sound signals - is modulated not only by the flash frequency (Fig. S2) but also by

262 the number of signals (i.e., mosquitoes in mating swarms, or LEDs in assembly) and the

263 wavelengths of flashing lights. Increasing the number of LEDs in assemblies increased the 
number of mosquitoes alighting on assemblies (Fig. 2, Exps. 1-3), suggesting that larger mating swarms, or swarms containing a higher percentage of females, are more attractive to mateseeking males. LED assemblies emitting UV light were as attractive to males as blue-light LED assemblies (Fig. 3, Exp. 4) which were more attractive than white-light LED (Fig. S3) assemblies. Whether equivalent physical characteristics of visual mate location signals affect the behaviour of females is not yet known. However, our findings that females, on average, alighted more often on LED assemblies flashing light at the male wingbeat frequency $(715 \mathrm{~Hz})$ than on LED assemblies emitting constant light (Fig. 7, Exp. 11), suggest that females may recognize a mating swarm, in part, based on the flashing lights 'produced' by swarming males.

With convincing data showing that visual and acoustic signals contribute to long- and shortrange mate location in Ae. aegypti (Fig. 4), there was ample incentive to also test the effect of a chemical signal, the female-produced pheromone, ${ }^{26}$ on responses of males. We predicted that female pheromone presented in combination with light and sound signals would modulate the behavior of males. However, the synthetic pheromone component ketoisophorone added to the bimodal complex of visual sound signals failed to express any additive or synergistic effect on the responses of males (Fig. 6, Exp. 10). It is conceivable, though, that the still-air setting of this experiment, with pheromone dissemination being entirely reliant on diffusion without forming a discrete pheromone plume, was not conducive for male attraction. Alternatively, in the absence of air current, pheromone may have built up in the room, ultimately disorienting males rather than guiding them to the pheromone source.

The sensory drive theory predicts functional links between signal design and presentation such that the conspicuousness of signals is maximized relative to environmental conditions and background noise. ${ }^{53}$ Previous reports in the literature and our data on Ae. aegypti and C. pipiens are in complete agreement with these predictions. The onset of the photophase induces swarm formation by male Ae. aegypti. ${ }^{43}$ With incident light reflecting off the wings of swarming males, their swarm becomes a visual beacon for other males and females in search for mates. As more mosquitoes enter the swarm, the "firework" of light flashes becomes larger and more attractive

291 (Fig. 2). The conspicuousness of the swarm display is further enhanced 3- to 4-times when 292 putting the light flash LED assembly on an oscillating shaker table, ${ }^{27}$ mimicking a swarm gently 293 swaying in the wind. In contrast, visual mate location systems hinging on incident sunlight reflecting off the wings of in-flight dipterans, as shown for bottle flies, house flies and black 
295

296

297

298

299

300

301

302

303

304

305

306

307

308

309

310

soldier flies, ${ }^{27,37}$ as well as yellow fever mosquitoes ${ }^{27}$ (also shown in this study), would not be expected to evolve in crepuscular mosquito species such as C. pipiens that swarm at dusk when sunlight is absent and illumination is dominated by diffuse light from the horizon. ${ }^{54}$ As predicted, LED assemblies flashing light at the reported wingbeat frequencies of C. pipiens $\left(350 \mathrm{~Hz},{ }^{44} 550\right.$ $\mathrm{Hz}^{34}$ ) had no signal characteristics for bioassay mosquitoes and prompted hardly any behavioral responses (Fig. S1, Exps. 12-14).

In conclusion, we describe that mate location or recognition in Ae. aegypti is mediated, in part, by long-range wingbeat light flash signals and by short-range wingbeat sound signals. The attractiveness of the light flash signals is dependent upon both the number of light flashes (i.e., mosquitoes in the swarm) and the wavelengths of the flashing light (i.e., light reflected off wings). As both male and female Ae. aegypti respond to light flash signals, these signals apparently contribute to the processes of forming and locating mating swarms. Moreover, with males and females having significantly different wingbeat frequencies, ${ }^{32,55}$ and thus light flash frequencies, the flash frequency could also facilitate long-range recognition of prospective mates. Our data address knowledge gaps as to how male and female Ae. aegypti, and possibly the sexes of other (diurnal) mosquitoes, find each other. ${ }^{31}$ Elucidating the mate location and courtship biology of mosquitoes will inform quality assessments of males that are mass-reared and released in sterile insect release tactics. Successful integration of these tactics into mosquito vector control programs ${ }^{56-58}$ hinges on sterile and transgenic males effectively competing with wild males for access to females.

\section{REFERENCES}

1. Gibson, G., and Torr, S. J. (1999). Visual and olfactory responses of haematophagous Diptera to host stimuli. Med. Vet. Entomol. 13, 2-23.

2. Bidlingmayer, W.L. (1994). How mosquitoes see traps: role of visual responses. J. Am. Mosq. Control Assoc. 10, 272-279.

3. McMeniman, C.J., Corfas, R.A., Matthews, B.J., Ritchie, S.A., and Vosshall, L.B. (2014). Multimodal integration of carbon dioxide and other sensory cues drives mosquito attraction to humans. Cell 156, 1060-1071. 
4. van Breugel, F., Riffell, J., Fairhall, A., and Dickinson, M.H. (2015). Mosquitoes use vision to associate odor plumes with thermal targets. Curr. Biol. 25, 2123-2129.

5. Gillies, M.T. (1980). The role of carbon dioxide in host-finding by mosquitoes (Diptera: Culicidae): a review. Bull. Entomol. Res. 70, 525-532.

6. Eiras, A.E., and Jepson, P.C. (1991). Host location by Aedes aegypti (Diptera: Culicidae): a wind tunnel study of chemical cues. Bull. Entomol. Res. 81, 151-160.

7. Healy, T.P., and Copland, M.J.W. (1995). Activation of Anopheles gambiae mosquitoes by carbon dioxide and human breath. Med. Vet. Entomol. 9, 331-336.

8. Geier, M., Bosch, O. J., and Boeckh, J. (1999). Influence of odour plume structure on upwind flight of mosquitoes towards hosts. J. Exp. Biol. 202, 1639-1648.

9. Dekker, T., and Cardé, R.T. (2011). Moment-to-moment flight manoeuvres of the female yellow fever mosquito (Aedes aegypti L.) in response to plumes of carbon dioxide and human skin odour. J. Exp. Biol. 214, 3480-3494.

10. Kröber, T., Kessler, S., Frei, J., Bourquin, M., and Guerin, P. M. (2010). An in vitro assay for testing mosquito repellents employing a warm body and carbon dioxide as a behavioral activator. J. Am. Mosq. Control Assoc. 26, 381-386.

11. Maekawa, E., Aonuma, H., Nelson, B., Yoshimura, A., Tokunaga, F., Fukumoto, S., and Kanuka, H. (2011). The role of proboscis of the malaria vector mosquito Anopheles stephensi in host-seeking behavior. Parasites Vectors 4, 10.

12. Kanda, F., Yagi, E., Fukuda, M., Nakajima, K., Ohta, T., and Nakata, O. (1990). Elucidation of chemical compounds responsible for foot malodour. Br. J. Dermatol. 122, 771-776.

13. Knols, B.G., van Loon, J.J., Cork, A., Robinson, R.D., Adam, W., Meijerink, J., De Jong, R. and Takken, W. (1997). Behavioural and electrophysiological responses of the female malaria mosquito Anopheles gambiae (Diptera: Culicidae) to Limburger cheese volatiles. Bulletin of Entomological Research 87, 151-159.

14. Gallagher, M., Wysocki, C.J., Leyden, J.J., Spielman, A.I., Sun, X., and Preti, G. (2008). Analyses of volatile organic compounds from human skin. Br. J. Dermatol. 159, 780-791. 
15. Khan, A.A., and Maibach, H.I. (1966). Quantitation of effect of several stimuli on landing and probing by Aedes aegypti. J. Econ. Entomol, 59, 902-905.

353 16. Browne, S.M., and Bennett, G.F. (1981). Response of mosquitoes (Diptera: Culicidae) to 354 visual stimuli. J. Med. Entomol. 18, 505-521.

355 17. Lacey, E.S., Ray, A., and Cardé, R.T. (2014). Close encounters: contributions of carbon 356 dioxide and human skin odour to finding and landing on a host in Aedes aegypti. Physiol. 357 Entomol. 39, 60-68.

358 18. Peach, D.A., Ko, E., Blake, A.J., and Gries, G. (2019). Ultraviolet inflorescence cues 359 enhance attractiveness of inflorescence odour to Culex pipiens mosquitoes. PloS one 14, $360 \quad \mathrm{e} 0217484$.

361 19. Downes, J.A. (1969). The swarming and mating flight of Diptera. Annu. Rev. Entomol. 14, $362 \quad 271-298$.

363 20. Knab, F. (1906). The swarming of Culex pipiens. Psyche (Camb. Mass.) 13, 123-133.

364 21. Charlwood, J.D., and Jones, M.D.R. (1980). Mating in the mosquito, Anopheles gambiae 365 s.1.II. Swarming behaviour. Physiol. Entomol. 5, 315-320.

366 22. Hartberg, W. K. (1971). Observations on the mating behaviour of Aedes aegypti in 367 nature. Bull. World Health Organ. 45, 847.

368 23. Yuval, B., and Bouskila, A. (1993). Temporal dynamics of mating and predation in mosquito 369 swarms. Oecologia 95, 65-69.

370 24. Yuval, B., Holliday-Hanson, M.L., and Washing, R.K. (1994). Energy budget of swarming 371 male mosquitoes. Ecol Entomol 19, 74-78.

372 25. Belton, P. (1994). Attraction of male mosquitoes to sound. J. Am. Mosq. Control Assoc. 10, $373 \quad 297-301$.

374 26. Fawaz, E.Y., Allan, S.A., Bernier, U.R., Obenauer, P.J., and Diclaro, J.W. (2014). Swarming 375 mechanisms in the yellow fever mosquito: aggregation pheromones are involved in the 376 mating behavior of Aedes aegypti. J. Vector Ecol. 39, 347-354. 
27. Gries, G.J., Hrabar, M.G., Stepanovic, L.C., Eichorn, C.E., Van Ryn, E.C., Brodie, B.S., Blake, A.J., and Thandi, R. (2017). PCT No. WO2017079680. Geneva, Switzerland: World Intellectual Property Organization.

28. Charlwood, J.D., and Jones, M.D.R. (1979). Mating behaviour in the mosquito, Anopheles gambiae s.1.I. Close range and contact behaviour. Physiol. Entomol. 4, 111-120.

29. Gopfert, M.C., Briegel, H., and Robert, D. (1999). Mosquito hearing: sound-induced antennal vibrations in male and female Aedes aegypti. J. Exp. Biol. 202, 2727-2738.

30. Gibson, G., Warren, B., and Russell, I.J. (2010). Humming in tune: sex and species recognition by mosquitoes on the wing. J. Assoc. Res. Otolaryngol. 11, 527-540.

31. Howell, P. I., and Knols, B.G. (2009). Male mating biology. Malar. J. 8, 1-10.

32. Cator, L.J., Arthur, B.J., Harrington, L.C., and Hoy, R.R. (2009). Harmonic convergence in the love songs of the dengue vector mosquito. Science 323, 1077-1079.

33. Gibson, G., and Russell, I. (2006). Flying in tune: sexual recognition in mosquitoes. Curr. Biol. 16, 1311-1316.

34. Gibson, G. (1985). Swarming behaviour of the mosquito Culex pipiens quinquefasciatus: a quantitative analysis. Physiol. Entomol. 10, 283-296.

35. Pennetier, C., Warren, B., Dabiré, K.R., Russell, I.J., and Gibson, G. (2010). "Singing on the wing" as a mechanism for species recognition in the malarial mosquito Anopheles gambiae. Curr. Biol. 20, 131-136.

36. Wishart, G., and Riordan, D. F. (1959). Flight responses to various sounds by adult males of Aedes aegypti (L.) (Diptera: Culicidae). Can. Entomol. 91, 181-191.

37. Eichorn, C., Hrabar, M., Van Ryn, E. C., Brodie, B. S., Blake, A. J., and Gries, G. (2017). How flies are flirting on the fly. BMC Biol. 15, 2. the heads and wings of Anastrepha suspensa (Loew) and Ceratitis capitata (Wiedemann) (Diptera: Tephritidae). Stud. Dipterol. 11, 313-322. 
39. Muir, L.E., Thorne, M.J., and Kay, B.H. (1992). Aedes aegypti (Diptera: Culicidae) vision: spectral sensitivity and other perceptual parameters of the female eye. J. Med. Entomol. 29, $278-281$.

40. Snow, W.F. (1971). The spectral sensitivity of Aedes aegypti (L.) at oviposition. Bull. Entomol. Res. 60, 683-696.

41. Kliewer, J.W., Miura, T., Husbands, R.C., and Hurst, C.H. (1966). Sex pheromones and mating behavior of Culiseta inornata (Diptera: Culicidae). Ann. Entomol. Soc. Am. 59, 530-

42. Nijhout, H.F., and Craig, G.B. (1971). Reproductive isolation in Stegomyia mosquitoes. III Evidence for a sexual pheromone. Entomol. Exp. Appl. 14, 399-412.

43. Cabrera, M., and Jaffe, K. (2007). An aggregation pheromone modulates lekking behavior in the vector mosquito Aedes aegypti (Diptera: Culicidae). J. Am. Mosq. Control Assoc. 23, 1-

44. Belton, P., and Costello, R.A. (1979). Flight sounds of the females of some mosquitoes of Western Canada. Entomol. Exp. Appl. 26, 105-114.

45. Miall, R.C. (1978). The flicker fusion frequencies of six laboratory insects, and the response of the compound eye to mains fluorescent 'ripple'. Physiol. Entomol. 3, 99-106.

46. Burkhardt, D. (1977). On the vision of insects. J. Comp. Physiol. B, Biochem. Syst. Environ. Physiol. 120, 33-50.

47. McClelland, G.A.H. (1959). Observations on the mosquito, Aëdes (Stegomyia) aegypti (L.), in East Africa. I.-The biting cycle in an outdoor population at Entebbe, Uganda. Bull.

48. Quraishi, M. S. (1965). Swarming, mating, and density in nature of Anopheles stephensi mysorensis. J. Econ. Entomol. 58, 821-824.

49. Roth, L. M. (1948). A study of mosquito behavior. An experimental laboratory study of the sexual behavior of Aedes aegypti (Linnaeus). Am. Midl. Nat. 40, 265-352. 
51. Cator, L.J., Arthur, B.J., Ponlawat, A., and Harrington, L.C. (2011). Behavioral observations and sound recordings of free-flight mating swarms of Ae. aegypti (Diptera: Culicidae) in Thailand. J. Med. Entomol. 48, 941-946.

52. Johnson, B.J., and Ritchie, S.A. (2015). The Siren's song: exploitation of female flight tones to passively capture male Aedes aegypti (Diptera: Culicidae). J. Med. Entomol. 53, 245-248. S125-S153.

54. Können, G.P. (1985) Polarized Light in Nature. (Cambridge University Press).

55. Brogdon, W.G. (1994). Measurement of flight tone differences between female Aedes aegypti and A. albopictus (Diptera: Culicidae). J. Med. Entomol. 31, 700-703.

56. Alphey, L., Benedict, M., Bellini, R., Clark, G.G., Dame, D.A., Service, M.W., and Dobson, S.L. (2010). Sterile-insect methods for control of mosquito-borne diseases: an analysis. Vector Borne Zoonotic Dis. 10, 295-311.

57. Lees, R.S., Gilles, J.R., Hendrichs, J., Vreysen, M.J., and Bourtzis, K. (2015). Back to the future: the sterile insect technique against mosquito disease vectors. Curr. Opin. Insect.

58. Yakob, L., and Walker, T. (2016). Alternative vector control methods to manage the Zika

59. Audacity Team (2019). Audacity: Free, open source, cross-platform audio software. URL https://www.audacityteam.org/.

60. mpv. A free, open source, and cross-platform media player. URL https://mpv.io/.

61. R Core Team (2020). R: A language and environment for statistical computing. R 


\section{ACKNOWLEDGEMENTS}

460 We thank Pawel Kowalski and Anthony Slater (electronics shop, SFU), and James Shoults

461 (machine shop, SFU), for assistance in designing and building experimental equipment, Amanda

462 Brooks for contributions to mosquito rearing and data collection, Regine Gries (RG) for

463 preparing pheromone lures, and GG and RG for feeding mosquitoes on their arms.

\section{AUTHOR CONTRIBUTIONS}

466 EK and GG conceived the study; EK and CL ran behavioural bioassays and scored data; AB and 467 EK analyzed data; AB, EK and CL obtained spectrometric data of visual test stimuli; ST and EK 468 produced and adjusted audio files; EK sourced and set up bioassay equipment; EK and GG 469 wrote the first draft, and all authors reviewed and approved of the final draft.

471 Funding: This study was supported by a Thelma Finlayson Graduate Entrance Scholarship and a

472 Thelma Finlayson Graduate Fellowship to EK, a Natural Sciences and Engineering Research

473 Council of Canada (NSERC) - Undergraduate Student Research Award to CL, and by an

474 NSERC - Industrial Research Chair to GG, with BASF Canada Inc. and Scotts Canada Ltd. as

475 the industrial sponsors.

\section{DECLARATION OF INTERESTS}

478 The authors declare no competing interests. The authors' industrial sponsors did not influence

479 the study design, data collection or other aspects of the study. The authors declare they do not

480 have competing financial or non-financial interests.

\section{METHODS}

483 KEY RESOURCES TABLE

\begin{tabular}{|c|c|c|}
\hline REAGENT or RESOURCE & SOURCE & IDENTIFIER \\
\hline \multicolumn{3}{|c|}{ Experimental models: organisms/strains } \\
\hline Culex pipiens laboratory colony & This paper & N/A \\
\hline Aedes aegypti laboratory colony & This paper & N/A \\
\hline \multicolumn{3}{|l|}{ Software and algorithms } \\
\hline Audacity & Audacity Team ${ }^{59}$ & $\begin{array}{l}\text { https://www.audacityte } \\
\text { am.org/ }\end{array}$ \\
\hline $\mathrm{mpv}$ & $m p v^{60}$ & https://mpv.io/ \\
\hline $\mathrm{R}$ & R Core Team $^{61}$ & $\begin{array}{l}\text { https://www.R- } \\
\text { project.org/ }\end{array}$ \\
\hline
\end{tabular}


bioRxiv preprint doi: https://doi.org/10.1101/2021.04.27.441577; this vergion posted April 27, 2021. The copyright holder for this preprint (which was not certified by peer review) is the author/funder, who has granted bioRxiv a license to display the preprint in perpetuity. It is made available under aCC-BY-NC-ND 4.0 International license.

\begin{tabular}{|c|c|c|}
\hline Raspbian 10 & $\begin{array}{l}\text { Raspberry Pi } \\
\text { Foundation, Cambridge, } \\
\text { UK }\end{array}$ & $\begin{array}{l}\text { https://www.raspberry } \\
\text { pi.org/software/operati } \\
\text { ng-systems/ }\end{array}$ \\
\hline SpectraSuite & Ocean Optics & $\begin{array}{l}\text { https://www.oceaninsi } \\
\text { ght.com/support/softw } \\
\text { are-downloads/ }\end{array}$ \\
\hline \multicolumn{3}{|l|}{ Other } \\
\hline $\mathrm{R}$ code for statistical analysis & This paper & $\begin{array}{l}\text { https://github.com/elto } \\
\text { n-ko/R-code-for- } \\
\text { mosquito-t- } \\
\text { test/blob/main/mosquit } \\
\text { o\%20proportion\%20st } \\
\text { at\%20test\%20- } \\
\text { \%20Copy.R }\end{array}$ \\
\hline $665 \mathrm{~Hz}$ sounds files used in acoustic experiments & This paper & \\
\hline $715 \mathrm{~Hz}$ sound files used in acoustic experiments & This paper & \\
\hline Raspberry Pi 3b+ & Cana Kit Corporation & $\begin{array}{l}\text { https://www.canakit.co } \\
\text { m/raspberry-pi-3- } \\
\text { model-b-plus-starter- } \\
\text { kit.html }\end{array}$ \\
\hline 5218268F White LEDs & Dialight & $\begin{array}{l}\text { http://www.dialightsig } \\
\text { nalsandcomponents.co } \\
\text { m/Product/Details/445 } \\
\text { 142/474752 }\end{array}$ \\
\hline TLHB5800 Blue LEDs & Vishay Intertechnology & $\begin{array}{l}\text { https://www.vishay.co } \\
\text { m/docs/83021/tlhb580 } \\
\text { 0.pdf }\end{array}$ \\
\hline EOLD-355-525 UV LEDs & OSA Opto Light GmbH & $\begin{array}{l}\text { https://www.osa- } \\
\text { opto.com/smd- } \\
\text { leds/eold-355-525.html }\end{array}$ \\
\hline HR-4000 Spectrophotometer & Ocean Optics & $\begin{array}{l}\text { https://www.oceaninsi } \\
\text { ght.com/products/spect } \\
\text { rometers/high- } \\
\text { resolution/hr-series/ }\end{array}$ \\
\hline Gould 20Ms/sec Digital Recording Oscilloscope & $\begin{array}{l}\text { Gould Electronics } \\
\text { GmbH }\end{array}$ & N/A \\
\hline
\end{tabular}

\section{Lead Contact}

486 Correspondence and requests for materials should be sent to the Lead Contact, Elton Ko

487 (eltonk@sfu.ca)

Materials Availability

490 This study did not generate new unique reagents. 
EXPERIMENTAL MODEL AND SUBJECT DETAILS

497 Aedes aegypti mosquitoes were reared in the insectary of the Burnaby campus of Simon Fraser 498 University (SFU) at 23-28 ${ }^{\circ} \mathrm{C}, \mathrm{RH} 40-60 \%$, and a photoperiod of 14L:10D. Adult mosquitoes 499 were kept in mesh cages $(30 \times 30 \times 46 \mathrm{~cm}$ high) provisioned with a 10-\% sucrose solution $\mathrm{ad}$ 500 libitum and allowed to blood-feed on the arm of GG or Regine Gries once a week. Three days 501 after blood-feeding, gravid females were offered an oviposition site consisting of a 354-mL 502 water-filled paper cup (Solo Cup Company, Lake Forest, IL, USA) lined with a paper towel 503 (Kruger Inc., Montreal, QC, Canada). For storage, egg-lined towels were inserted into Ziploc 504 bags (S.C. Johnson \& Son, Inc., Racine, WI, USA) kept at 23-28 ${ }^{\circ} \mathrm{C}$. To initiate a new generation of mosquitoes, towels were transferred to a glass dish $(10 \mathrm{~cm}$ diam $\times 5 \mathrm{~cm}$ high), containing water enriched with brewer's yeast (U.S. Biological Life Sciences, Salem, MA, USA). After egg hatching, $1^{\text {st }}$ instar larvae were transferred to water-filled trays $(45 \times 25 \times 7 \mathrm{~cm} \mathrm{high})$ and provisioned with NutraFin Basix tropical fish food (Rolf C Hagen Inc., Montreal, QC, Ca). Using a 7-mL plastic pipette (VWR International, Radnor, PA, USA), pupae were transferred to water-filled Solo Cups covered with a mesh lid and fitted with a sucrose solution-soaked cotton ball to sustain adult mosquitoes eclosing over the course of $72 \mathrm{~h}$. These mosquitoes were then released into mesh cages $(30 \times 30 \times 46 \mathrm{~cm}$ high $)$ and separated by sex for use in bioassays when they were 2-7 days old (males) or 5-10 days old (females).

The rearing protocol for $C$. pipiens resembled that for Ae. aegypti except that $(i)$ rooms were

515 kept at $23-26^{\circ} \mathrm{C}$, (ii) gravid females were offered a glass dish (10 cm diam $\times 5 \mathrm{~cm}$ high $)$ as 516 oviposition site, and (iii) egg rafts - rather than egg-lined towels - were transferred to water-

517 filled trays for larval development. Only 2- to 7-day-old males were tested in bioassays.

\section{METHOD DETAILS}

520 LEDs

521 Spectra of white LEDs (5218268F, Dialight, London, UK), blue LEDs (TLHB5800, Vishay 522 Intertechnology, Malvern, PA, USA) and UV LEDs (EOLD-355-525, OSA Opto Light GmbH, 523 Berlin, Germany) (Fig. S4) were recorded with a spectrophotometer (HR-4000, Ocean Optics) 524 and SpectraSuite software (Ocean Optics). The photon flux of each LED was sampled at a 525 distance of $5 \mathrm{~cm}$ from the cosine corrector connected to the sampling fibre of the spectrometer. 
526 This allowed use to vary the amperage supplied to the LEDs in order to achieve an intensity of

$5272 \mathrm{e}^{15} \mathrm{photons} / \mathrm{cm}^{2} / \mathrm{s}$. Using a lathe, the lens of each LED was flattened to widen the angle of

528 emitted light. The frequency $(\mathrm{Hz})$ and the duty cycle (set to 3\%) of each LED were verified using

529 an oscilloscope (Gould 20Ms/sec Digital Recording Oscilloscope, Gould Electronics GmbH,

530 Eichstetten am Kaiserstuhl, Germany).

\section{Design of LED arrays}

533 LED arrays consisted of up to 16 LEDs arranged in a three-dimensional circular shape $(\sim 15-\mathrm{cm}$ 534 diam) (Fig. 1B). Each LED was mounted upward-facing 18-23 cm above ground on a separate, 535 rigid stalk which was attached to a ring stand, the base of which was covered with Cheesecloth 536 (Cheesecloth Wipes, VWR International, PA, USA) to minimize light reflectance (Fig. 1B). 537 Each LED was connected to one channel of a 16-channel pulse generator (5-Volt, 2-Amp) 538 designed and built by the Science Technical Centre at SFU to allow independent control of test 539 variables for each LED, including duty cycle, frequency $(\mathrm{Hz})$, amperage and periodicity.

\section{General design of small-space behavioural experiments}

542 We ran behavioural bioassays with mosquitoes in a mesh cage $(61 \times 61 \times 61 \mathrm{~cm})$ (BioQuip

543 Products, Inc., CA, USA) (Fig. 1A,B), with the cage bottom and the front and side walls covered 544 with cheesecloth to minimize stray light entry and light reflectance. A lamp fitted with an LED

545 bulb (Feit Electric, Pico Rivera, CA, USA; Fig. S5) was placed above the rear edge of the cage to 546 provide illumination during bioassays. For each 20-min bioassay, we placed two LED arrays (see 547 above) $15 \mathrm{~cm}$ apart from each other in the centre of the cage (alternating their position between 548 replicates) and released 50 2- to 7-day-old sexually mature males (Exps. 1-10, 12-14), or 50 5- to 549 10-day-old sexually mature females (Exp. 11), into the cage. To video-record alighting 550 responses of mosquitos on LEDs, we placed an AKASO EK7000 action camera (AKASO, 551 Frederick, MD, USA) on top of the cage (Fig. 1C). Mosquito contacts and landings on LEDs, or 552 on a stalk within $2.5 \mathrm{~cm}$ of an LED, were recorded as responses. During bioassays, rooms were 553 maintained at a temperature of $23-28{ }^{\circ} \mathrm{C}$ and $40-60 \%$ relative humidity. After each bioassay, the 554 camera was stopped and the cage was opened to release the mosquitoes which were then 555 euthanized with an electric fly swatter (Guangzhou Sidianjin Trading Co., Guangzhou, China). 556 To optimize the responsiveness of Ae. aegypti females and males in all bioassays (see also 
557 below), we tested them only on sunny or overcast (but not rainy) days and only during the light

558 phase of their photoperiod (14L:10D).

\section{General design of large-space behavioural experiments}

561 In a cubicle $(2.25 \times 2.1 \times 2.4 \mathrm{~m}$ high; Fig. $1 \mathrm{D})$ of the insectary illuminated by ceiling fluorescent 562 lighting (F32T8/SPX50/ECO, General Electric, Boston, MA, USA; Fig. S5), two LED arrays 563 were placed on a counter $164 \mathrm{~cm}$ apart from each other, and $43 \mathrm{~cm}$ and $30 \mathrm{~cm}$, respectively, 564 away from the back and side walls of the cubicle (Fig. 1E). For each bioassay, 50 2- to 7-day-old sexually mature males were released into the cubicle through the cubicle door. Their alighting

566 responses on LEDs were video-record with an AKASO action camera placed in a metal sieve 567 (shielding the camera's electromagnetic field) (Fig. 1F) mounted on a ring stand $42 \mathrm{~cm}$ above each LED array. During bioassays, rooms were kept at $23-28{ }^{\circ} \mathrm{C}$ and $40-60 \%$ relative humidity. After 20 min of recordings, the cameras were turned off, all mosquitoes were euthanized with an electric fly swatter, and the position of LED array 1 and 2 was reversed for the next replicate.

\section{Wingbeat sound cues}

573 To determine the effect of mosquito wing beat sound on LED-alighting responses of bioassay 574 mosquitoes, we used Audacity $2.3 .2^{59}$ to prepare eight sound files (see Supplementary Material)

575 with paired channels, one of which was randomly assigned to the treatment stimulus and the 576 other to the control stimulus. Treatment stimuli consisted of wingbeat sound characteristic of Ae. 577 aegypti females $(665 \mathrm{~Hz})$ or males $(715 \mathrm{~Hz})$, whereas control stimuli consisted of white noise

578 (sound that covers the entire range of audible frequencies). Audio tracks of wing beat

579 frequencies or white noise were played in parallel, Doppler-shifting upwards, holding steady, or 580 Doppler-shifting downwards to silence, each of these three phases lasting $7 \mathrm{~s}$. The intensity level 581 of the wing beat sound and the white noise control stimulus were each adjusted to $10 \mathrm{dBL}$ above 582 background ( $\mathrm{SPL}=45 \mathrm{dBL})$, measured $2.5 \mathrm{~cm}$ away from each sound-emitting earbud speaker 583 (RPHJE120K, Panasonic, Osaka Prefecture, Japan), using a 1551-C sound level meter fitted with 584 a Type 1560-PB microphone (General Radio Company, Concord, MA, USA). Earbud-emitted 585 sound was not audible to human hearing at $50 \mathrm{~cm}$ away from the source. Each headphone pair 586 played back either an artificial tone $(665 \mathrm{~Hz}, 715 \mathrm{~Hz})$, white noise or was kept silent, depending 
on the array (treatment or control) and the experiment. Sound files were played using MPV media player. ${ }^{60}$

To reduce the directionality of sound stimuli, we removed the rubber tip from each earbud. On both arrays, each of eight LEDs was paired with a single upward-facing earbud which was attached with a twist tie to the LED-carrying stalk $2 \mathrm{~cm}$ below the LED (Fig. 1G). Earbud wires on the cage floor were covered with cheesecloth and routed out of the cage through a mesh sleeve. Each pair of earbuds (one earbud being assigned to the treatment array and the other to the control array) was plugged into a separate USB sound card (C-Media HS-100B Chipset, TROND, Shenzhen, China) which, in turn, was plugged into a 4-port USB hub (Qicent, Shenzhen, China) (Fig. 1H). Connecting only two soundcards to each of four USB hubs helped avoid latency of playback recordings. The USB hubs were plugged into a Raspberry Pi 3 B+ computer (Cana Kit Corporation, North Vancouver, BC, Ca), running Raspbian 10 (Raspberry Pi Foundation, Cambridge, UK).

\section{Specific experiments}

602 H1: The attractiveness of a mating swarm (i.e., array of light-flashing LEDs) is dependent upon 603 swarm size (i.e., number of LEDs in array)

604 To determine the effect of LED numbers in array (i.e., 'mosquito swarm size') on array 605 attractiveness (Exps. 1-3; $\mathrm{n}=10$ each; Table 1), we presented groups of 50 Ae. aegypti males 606 each with a choice of two LED arrays that differed in number of LEDs. Specifically, we tested 607 arrays with eight $v s$ one LED (Exp. 1), eight $v s$ four LEDs (Exp. 2), and eight vs 16 LEDs (Exp.

608 3). Each LED in each array flashed blue light at $665 \mathrm{~Hz}$.

H2: The attractiveness of a mating swarm (i.e., array of light-flashing LEDs) is dependent upon the spectral composition of wing flashes (i.e., light emitted by LEDs)

612 The effect of LED wavelength (UV or blue) on LED-alighting responses by Ae. aegypti males 613 was tested by offering groups of 50 males each a choice between two 8-LED arrays flashing

614 either UV or blue light at $665 \mathrm{~Hz}$ (the light flash frequency of flying females) (Exp. 4, $\mathrm{n}=10$;

615 Table 1). The amperage supplied to LEDs was modulated to an equal photon flux from the blue 616 and UV LEDs. 
619 attraction signals, respectively

620 To test whether wingbeat light flashes $(665 \mathrm{~Hz})$ of Ae. aegypti females are long-range male 621 attraction signals, we ran a two-choice experiment in both a small setting $(61 \times 61 \times 61 \mathrm{~cm}$; Exp.

$6225, \mathrm{n}=10$; Fig. 1A,B) and a large setting $(225 \times 210 \times 240 \mathrm{~cm}$ high; Exp. 6, n = 10; Fig. 1D,E;

623 Table1). In each experiment, we offered groups of 50 males each a choice between two 8-LED

624 arrays which were separated by $15 \mathrm{~cm}$ (Exp. 5) or $164 \mathrm{~cm}$ (Exp. 6). In both experiments, the

625 LEDs of array 1 emitted blue light flashes of $665 \mathrm{~Hz}$, whereas the LEDs of array 2 emitted 626 constant blue light. Each LED in both arrays was coupled with an earbud speaker emitting the 627 females' wingbeat sound $(665 \mathrm{~Hz})$.

628 To test whether wingbeat sounds $(665 \mathrm{~Hz})$ of Ae. aegypti females are short-range mate recognition signals for males, we ran a small setting experiment, offering males a choice between

630 two 8-LED arrays separated by $15 \mathrm{~cm}$. The LEDs of both arrays emitted blue light flashes at 665

$631 \mathrm{~Hz}$. The earbud speakers of array 1 emitted female wingbeat sound $(665 \mathrm{~Hz})$, whereas speakers

632 of array 2 emitted white noise (Table 1; Exp. 7, $\mathrm{n}=10$ ). To determine whether white noise may

633 have had a repellent effect on the males' responses in Experiment 7, speakers of array 2 were

634 kept silent in follow-up experiment $8(\mathrm{n}=10)$ which otherwise was identical (Table 1). To

635 further investigate whether mate recognition cues of males deter males, we offered groups of 50

636 males each a choice between two 8-LED arrays emitting blue light flashes at $715 \mathrm{~Hz}$ (the wing

637 flash frequency of males), with earbud speakers of array 1 emitting male wing beat sound (715

$638 \mathrm{~Hz}$ ) and speakers of array 2 broadcasting white noise (Table 1; Exp. 9, $\mathrm{n}=10$ ).

H4: Swarm pheromone of Ae. aegypti females increases the attractiveness of their wingbeat light 641 flashes and sound

642 To test whether the swarm pheromone component ketoisophorone increases the attractiveness of

643 the females' wingbeat light flashes and sound, we ran a large setting (room) experiment (Fig.

644 1D,E; Table 1; Exp. 10, n = 9), offering groups of 50 males each a choice between two 8-LED

645 arrays separated by $164 \mathrm{~cm}$. All LEDs and earbud speakers of both arrays emitted blue light

646 flashes $(665 \mathrm{~Hz})$ and the corresponding wingbeat sound $(665 \mathrm{~Hz})$. The bases of both arrays were

647 fitted with a filter paper-lined watch glass which was treated with either ketoisophorone $(300 \mu \mathrm{g})$ 
in pentane-ether $(30 \mu \mathrm{l})$ (array 1) or a pentane-ether control (30 $\mu \mathrm{l})$ (Fig. 1 I). The solvent was allowed to evaporate completely prior to the onset of each bioassay.

H5: Wing beat light flashes of Ae. aegypti males are attractive to mate-seeking females

652 To determine whether wing beat light flashes of Ae. aegypti males are attractive to mate-seeking

653 females, we ran a small-setting (cage) experiment, offering groups of 50 females each a choice

654 between two 8-LED arrays separated by $15 \mathrm{~cm}$ and deprived of all earbud speakers. All LEDs of

655 array 1 emitted constant white light, whereas all LEDs of array 2 emitted white light flashes (715

$656 \mathrm{~Hz})($ Table 1; Exp. 11, $\mathrm{n}=13)$.

H6: Dusk-swarming C. pipiens do not exploit wingbeat light flashes for mate attraction

659 To determine whether dusk-swarming $C$. pipiens use wingbeat light flashes as mate recognition

660 cues, we ran three small-setting experiments, offering groups of 50 2- to 7-day-old males a

661 choice between two 8-LED arrays separated by $15 \mathrm{~cm}$ and deprived of all earbud speakers. All

662 LEDs of array 1 emitted constant white light, whereas all LEDs of array 2 emitted white light

663 flashes at either $350 \mathrm{~Hz}($ Exp. 12, $\mathrm{n}=10)$ or $550 \mathrm{~Hz}$ (Exps. 13, 14, $\mathrm{n}=10$ each; Table 1), two

664 previously reported wingbeat frequencies of female C. pipiens. ${ }^{34,44}$ Experiments 12 and 13

665 followed the 'general design of small-space behavioural experiments' (see above).

666 Taking into account that $C$. pipiens forms mating swarms at dusk, the room lights in follow-

667 up experiment 14 were turned off and the bioassay cage was illuminated from behind by an LED

668 bulb (Feit Electric, Pico Rivera, CA, USA; Fig. S5) set by a dimmer (TBL03, Leviton

669 Manufacturing Company, Inc., Melville, NY, USA) to a light intensity level of 1 Lux at the cage

670 centre (Gibson 1985). Likewise, the photon flux of LEDs in arrays 1 and 2 emitting constant

671 light and flashing light, respectively, was reduced to $6.67 \mathrm{e}^{12}$ photons $/ \mathrm{cm}^{2} / \mathrm{s}$ in accordance with

672 the low light level in the room. To facilitate recordings of alighting responses by mosquitoes on

673 LEDs, we used a hunting camera (Campark Trail Camera, Campark Electronics Co., Ltd, Hong

674 Kong) with an IR-sensitive wavelength range which mosquitoes cannot perceive.

\section{Statistical analyses}


678 We used R 3.6.2 $2^{61}$ to analyse behavioural data. Mean proportions of contact and alighting

679 responses by mosquitoes were analyzed with logistic regression using generalized linear models.

680 In order to determine whether proportions differed between arrays, we compared an intercept

681 only model to a null model with a likelihood ratio test. We then used back-transformed

682 coefficients from those models to obtain mean and standard errors for the proportion of

683 mosquitos responding to each array. 
Table 1 Details of cues or signals [wingbeat light flash, wingbeat sound, pheromone (Phero)] tested in small-space (SS: $61 \times 61 \times 61 \mathrm{~cm}$ ) and large space (LS: $2.25 \times 2.1 \times 2.4 \mathrm{~m}$ ) behavioral bioassays (see Fig. 1 for experimental design) with Aedes aegypti (Exps. 1-12) and Culex pipiens (Exps. 13-14)

\begin{tabular}{|c|c|c|c|c|c|}
\hline & Stimulus 1 & & Stimulus 2 & & \\
\hline $\begin{array}{l}\text { Exp. \# } \\
\text { Range }\end{array}$ & Light flash & Phero & Light flash & Sound & Phero \\
\hline
\end{tabular}

H1: The attractiveness of an Ae. aegypti mating swarm (array of light-flashing LEDs) depends upon the number of mosquitoes in the swarm (number of LEDs in the array)

\begin{tabular}{llll|llr}
1 & $\begin{array}{l}\text { 1 LED } \\
\text { SS }\end{array}$ & Silent $; 665 \mathrm{~Hz})$ & No & $\begin{array}{l}8 \mathrm{LED} \\
\text { (blue; } 665 \mathrm{~Hz})\end{array}$ & Silent & No \\
2 & $\begin{array}{l}\text { 4 LEDs } \\
\text { (blue; } 665 \mathrm{~Hz})\end{array}$ & Silent & No & $\begin{array}{l}8 \text { LEDs } \\
\text { (blue; } 665 \mathrm{~Hz})\end{array}$ & Silent \\
3 & $\begin{array}{l}16 \mathrm{LEDs} \\
\text { (blue; } 665 \mathrm{~Hz})\end{array}$ & Silent & No & $\begin{array}{l}8 \mathrm{LEDs} \\
\text { (blue; } 665 \mathrm{~Hz})\end{array}$ & Silent & No \\
SS & & &
\end{tabular}

H2: The attractiveness of an Ae. aegypti mating swarm (i.e., array of light-flashing LEDs) is dependent upon the spectral composition of wing flashes (i.e., light emitted by LEDs)

\begin{tabular}{|c|c|c|c|c|c|}
\hline $\begin{array}{l}4 \\
\text { SS }\end{array}$ & $\begin{array}{l}8 \text { LEDs } \\
\text { (UV; } 665 \mathrm{~Hz} \text { ) }\end{array}$ & Silent & No & $\begin{array}{l}8 \text { LEDs } \\
\text { (blue; } 665 \mathrm{~Hz} \text { ) }\end{array}$ & Silent \\
\hline
\end{tabular}

H3: Wing beat light flashes and sound of Ae. aegypti females are long-and short-range male attraction signals, respectively

\begin{tabular}{|c|c|c|c|c|c|c|}
\hline $\begin{array}{l}5 \\
\text { SS }\end{array}$ & $\begin{array}{l}8 \text { LEDs } \\
\text { (blue; } 665 \mathrm{~Hz} \text { ) }\end{array}$ & $\begin{array}{l}\text { Wingbeat sound } \\
\text { (female: } 665 \mathrm{~Hz} \text { ) }\end{array}$ & No & $\begin{array}{l}8 \text { LEDs } \\
\text { (blue; constant) }\end{array}$ & $\begin{array}{l}\text { Wingbeat sound } \\
\text { (female: } 665 \mathrm{~Hz} \text { ) }\end{array}$ & No \\
\hline $\begin{array}{l}6 \\
\mathrm{LS}\end{array}$ & $\begin{array}{l}8 \text { LEDs } \\
\text { (blue; } 665 \mathrm{~Hz} \text { ) }\end{array}$ & $\begin{array}{l}\text { Wingbeat sound } \\
\text { (female: } 665 \mathrm{~Hz} \text { ) }\end{array}$ & No & $\begin{array}{l}8 \text { LEDs } \\
\text { (blue; constant) }\end{array}$ & $\begin{array}{l}\text { Wingbeat sound } \\
\text { (female: } 665 \mathrm{~Hz} \text { ) }\end{array}$ & No \\
\hline $\begin{array}{l}7 \\
\text { SS }\end{array}$ & $\begin{array}{l}8 \text { LEDs } \\
\text { (blue; } 665 \mathrm{~Hz} \text { ) }\end{array}$ & $\begin{array}{l}\text { Wingbeat sound } \\
\text { (female: } 665 \mathrm{~Hz} \text { ) }\end{array}$ & No & $\begin{array}{l}8 \text { LEDs } \\
\text { (blue; } 665 \mathrm{~Hz} \text { ) }\end{array}$ & White noise & No \\
\hline $\begin{array}{l}8 \\
\text { SS }\end{array}$ & $\begin{array}{l}8 \text { LEDs } \\
\text { (blue; } 665 \mathrm{~Hz} \text { ) }\end{array}$ & $\begin{array}{l}\text { Wingbeat sound } \\
\text { (female: } 665 \mathrm{~Hz} \text { ) }\end{array}$ & No & $\begin{array}{l}8 \text { LEDs } \\
\text { (blue; } 665 \mathrm{~Hz} \text { ) }\end{array}$ & Silent & No \\
\hline $\begin{array}{l}9 \\
\text { SS }\end{array}$ & $\begin{array}{l}8 \text { LEDs } \\
\text { (blue; } 715 \mathrm{~Hz} \text { ) }\end{array}$ & $\begin{array}{l}\text { Wingbeat sound } \\
\text { (male: } 715 \mathrm{~Hz} \text { ) }\end{array}$ & No & $\begin{array}{l}8 \text { LEDs } \\
\text { (blue; } 715 \mathrm{~Hz} \text { ) }\end{array}$ & White noise & No \\
\hline
\end{tabular}

H4: Swarm pheromone of Ae. aegypti females increases the attractiveness of their wingbeat light flashes and sound

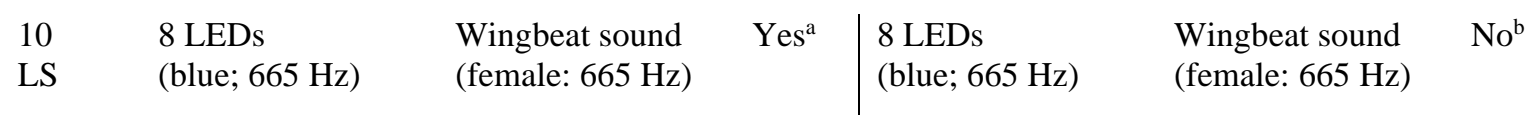

H5: Wing beat light flashes of Ae. aegypti males are attractive to mate-seeking females
$11 \quad 8$ LEDs No
SS (blue; constant)
No
No $\quad 8$ LEDs No
(blue; $715 \mathrm{~Hz}$ )
No

H6: Dusk-swarming C. pipiens do not use wingbeat light flashes for mate recognition

\begin{tabular}{|c|c|c|c|c|c|c|}
\hline $\begin{array}{l}12 \\
\text { SS }\end{array}$ & $\begin{array}{l}8 \text { LEDs } \\
\text { (white; } 350 \mathrm{~Hz} \text { ) }\end{array}$ & No & No & $\begin{array}{l}8 \text { LEDs } \\
\text { (white; constant) }\end{array}$ & No & No \\
\hline $\begin{array}{l}13 \\
\text { SS }\end{array}$ & $\begin{array}{l}8 \text { LEDs } \\
\text { (white; } 550 \mathrm{~Hz} \text { ) }\end{array}$ & No & No & $\begin{array}{l}8 \text { LEDs } \\
\text { (white; constant) }\end{array}$ & No & No \\
\hline $\begin{array}{l}14^{\mathrm{c}} \\
\mathrm{SS}\end{array}$ & $\begin{array}{l}8 \text { LEDs } \\
\text { (white; } 550 \mathrm{~Hz} \text { ) }\end{array}$ & No & No & $\begin{array}{l}8 \text { LEDs } \\
\text { (white; constant) }\end{array}$ & No & No \\
\hline
\end{tabular}


bioRxiv preprint doi: https://doi.org/10.1101/2021.04.27.441577; this varGon posted April 27, 2021. The copyright holder for this preprint (which

was not certified by peer review) is the author/funder, who has granted bioRxiv a license to display the preprint in perpetuity. It is made available under aCC-BY-NC-ND 4.0 International license.

$684{ }^{\mathrm{a}}$ ketoisophorone $(300 \mu \mathrm{g})$ in pentane-ether $(30 \mu \mathrm{l})$ applied onto filter paper; ${ }^{\mathrm{b}}$ pentane-ether $(30 \mu \mathrm{l})$ applied onto 685 filter paper. ${ }^{c}$ Exp. 14 was run at low room lighting (1 lux) and with dimmed LEDs $\left(6.67 \mathrm{e}^{12}\right.$ photons $\left./ \mathrm{cm}^{2} / \mathrm{s}\right)$.

686

687

688

689

690

691

692

693

694

695

696

697

698 

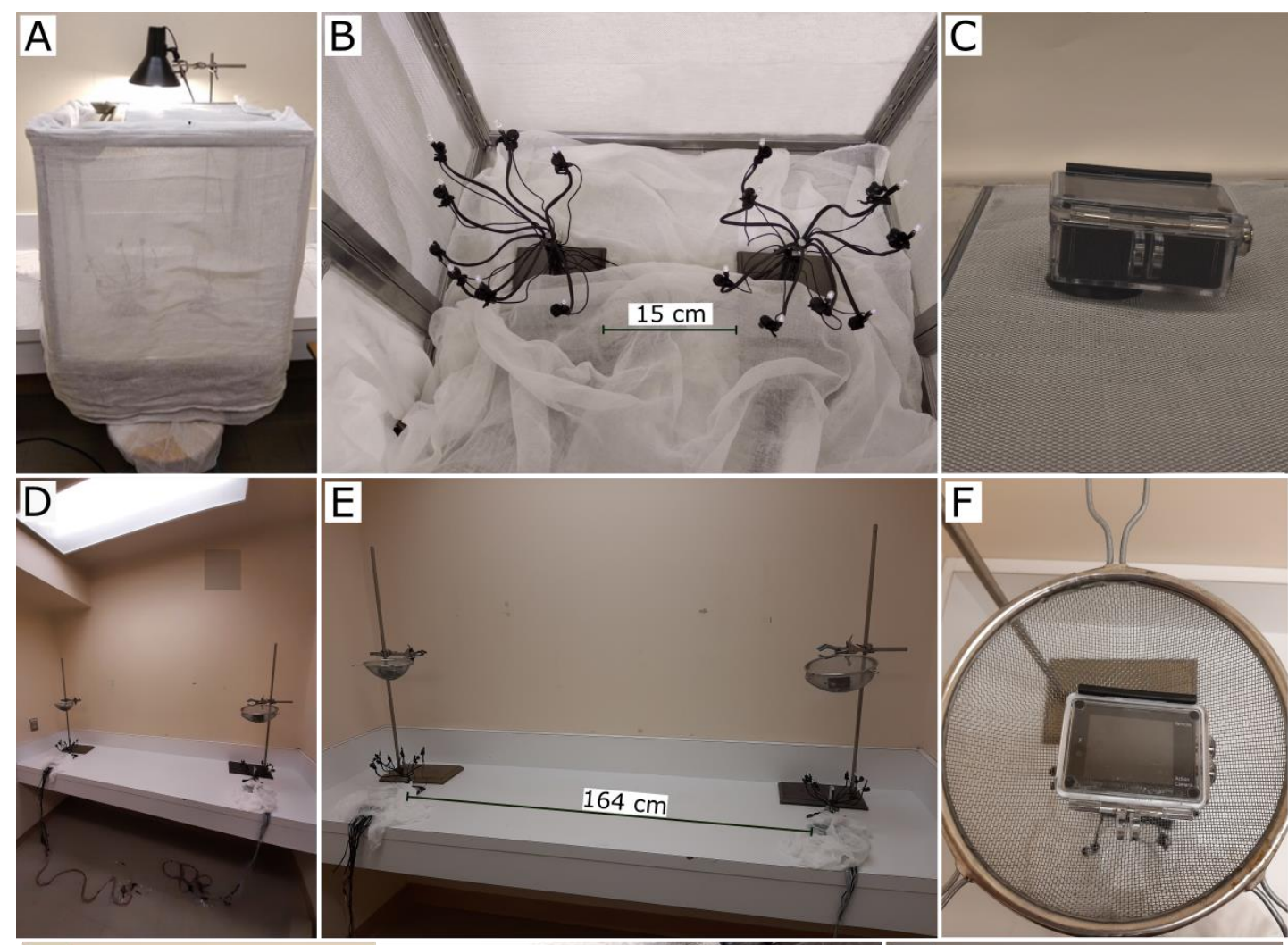

\section{G}
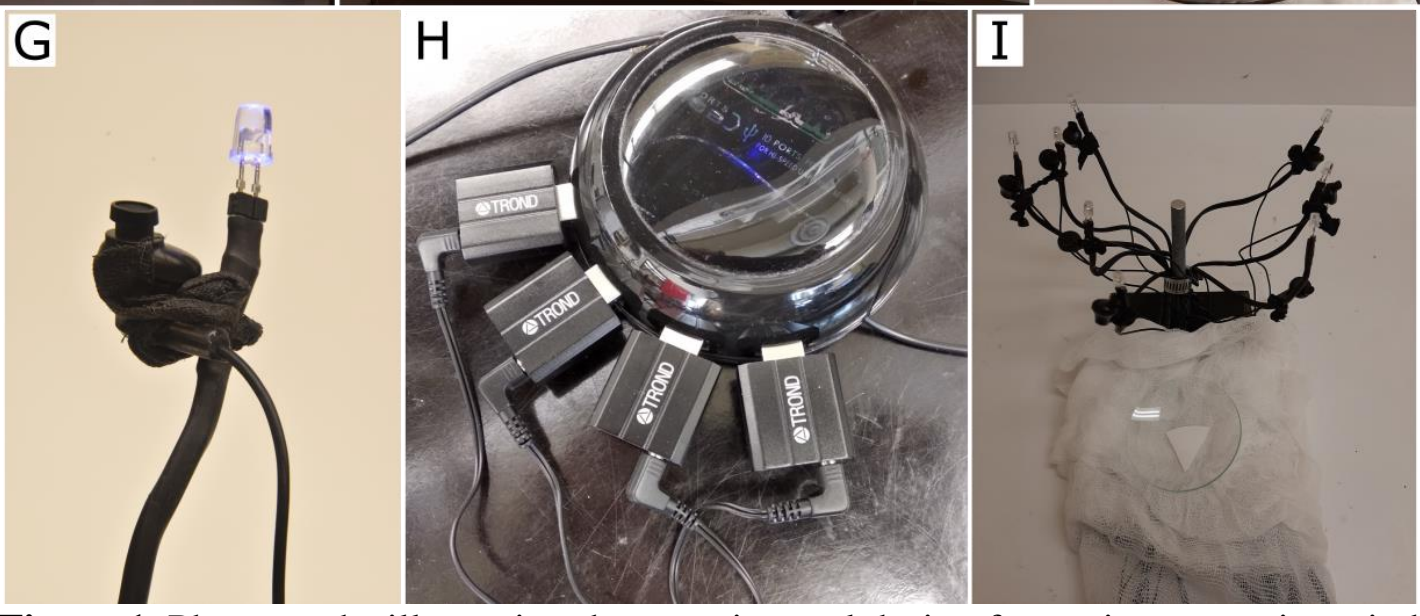

Figure 1. Photographs illustrating the experimental design for testing mosquitoes in behavioural bioassays. (A-C) External and internal views of the small-space bioassay arena (wire mesh cage: $61 \times 61 \times 61 \mathrm{~cm})$, depicting two assemblies of eight light emitting diodes (LED) each $(\mathbf{B})$, and a video camera on top of the cage $(\mathbf{C})$ for recording alighting responses of mosquitoes on LED assemblies; (D-F) Views of the large-space bioassay room $(225 \times 210 \times 240 \mathrm{~cm})$, with a video camera inside a metal sieve $(\mathbf{F})$ positioned above each of two widely-spaced LED assemblies. The sieve blocked potential electromagnetic waves emanating from the camera. Light was provided via two fluorescent bulbs in the ceiling fixture (for spectral composition see Supplementary Information); (G-I) Details of the experimental design showing a paired LED/earbud speaker mounted on a single arm of the 8-LED assembly $(\mathbf{G})$, the USB hub with USB sound cards driving earbud speakers $(\mathbf{H})$, and a glass dish containing a piece of pheromoneor solvent-treated filter paper (I) deployed in a pheromone experiment. 


\section{Small space}
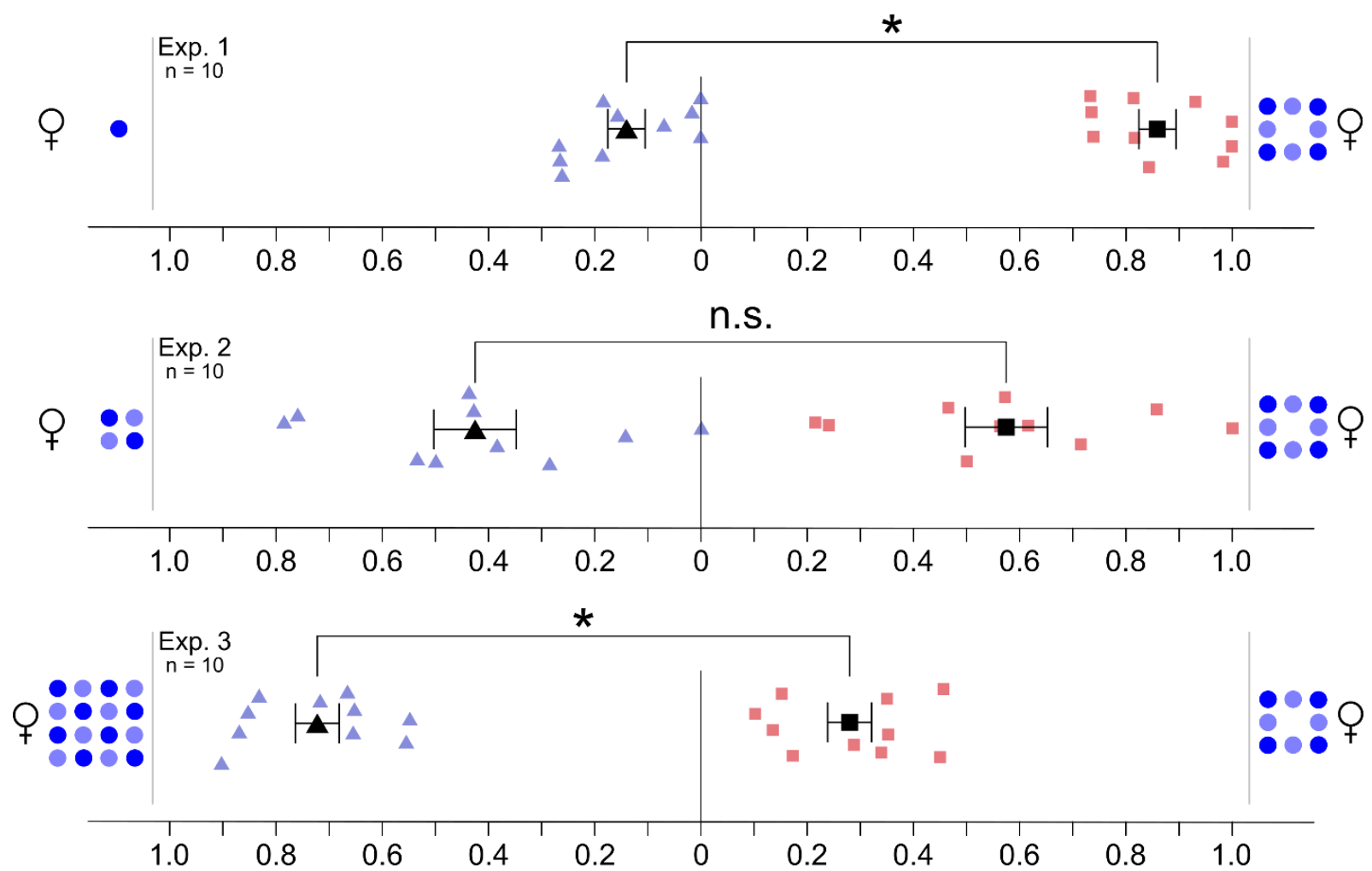

Proportion of total alightings by males on test stimuli

\section{Figure 2. Effect of LED numbers in assemblies on alighting responses of 2- to 7-day-old}

715 male Aedes aegypti. Numbers of blue dots represent the number of LEDs contained within each

716 of two LED arrays (Fig. 1B) flashing blue light at the $665-\mathrm{Hz}$ wingbeat frequency of female Ae.

717 aegypti. Each replicate was run with 50 males. Light blue triangles and light red squares show

718 the data of individual replicates and black symbols the mean ( \pm SE). An asterisk indicates a

719 significant preference (binary logistic regression model; $\mathrm{p}<0.05 ; \mathrm{n}$. s. = not significant). 
Small space

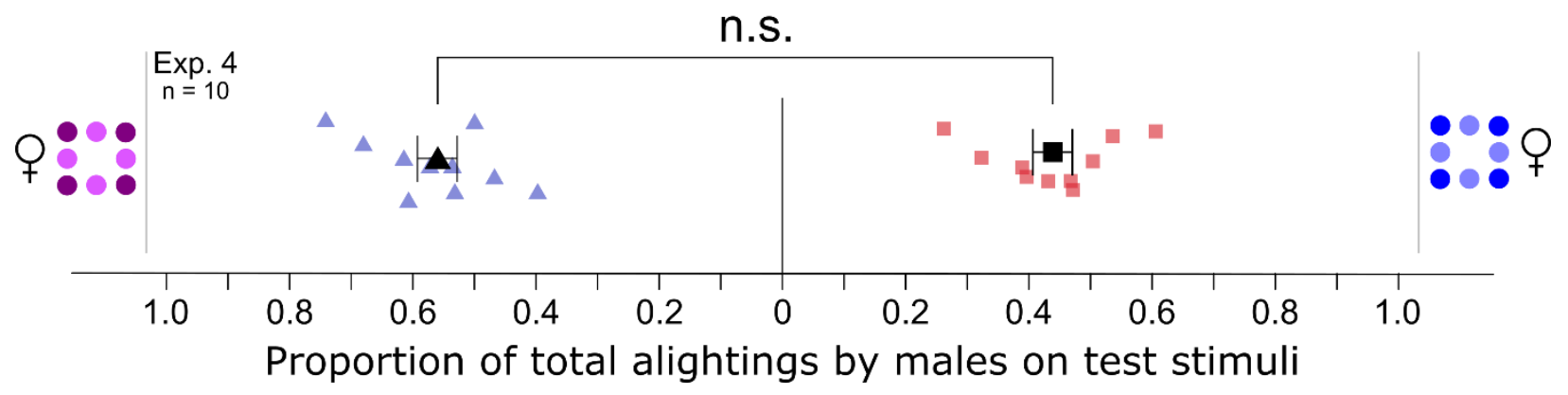

726 Figure 3. Effect of wavelength on alighting responses of 2- to 7-day old male Aedes aegypti.

727 The eight purple and eight blue dots represent the number of LEDs contained within each of two

728 LED arrays (Fig. 1B), one of which was flashing UV light and the other blue light at the 665-Hz

729 wingbeat frequency of female Ae. aegypti. Each replicate was run with 50 males. Light blue

730 triangles and light red squares show the data of individual replicates and black symbols the mean

$731 \quad \pm$ SE). There was no preference for either set of test stimuli (binary logistic regression model; $p$

$732>0.05 ;$ n. s. $=$ not significant). 


\section{Small space}
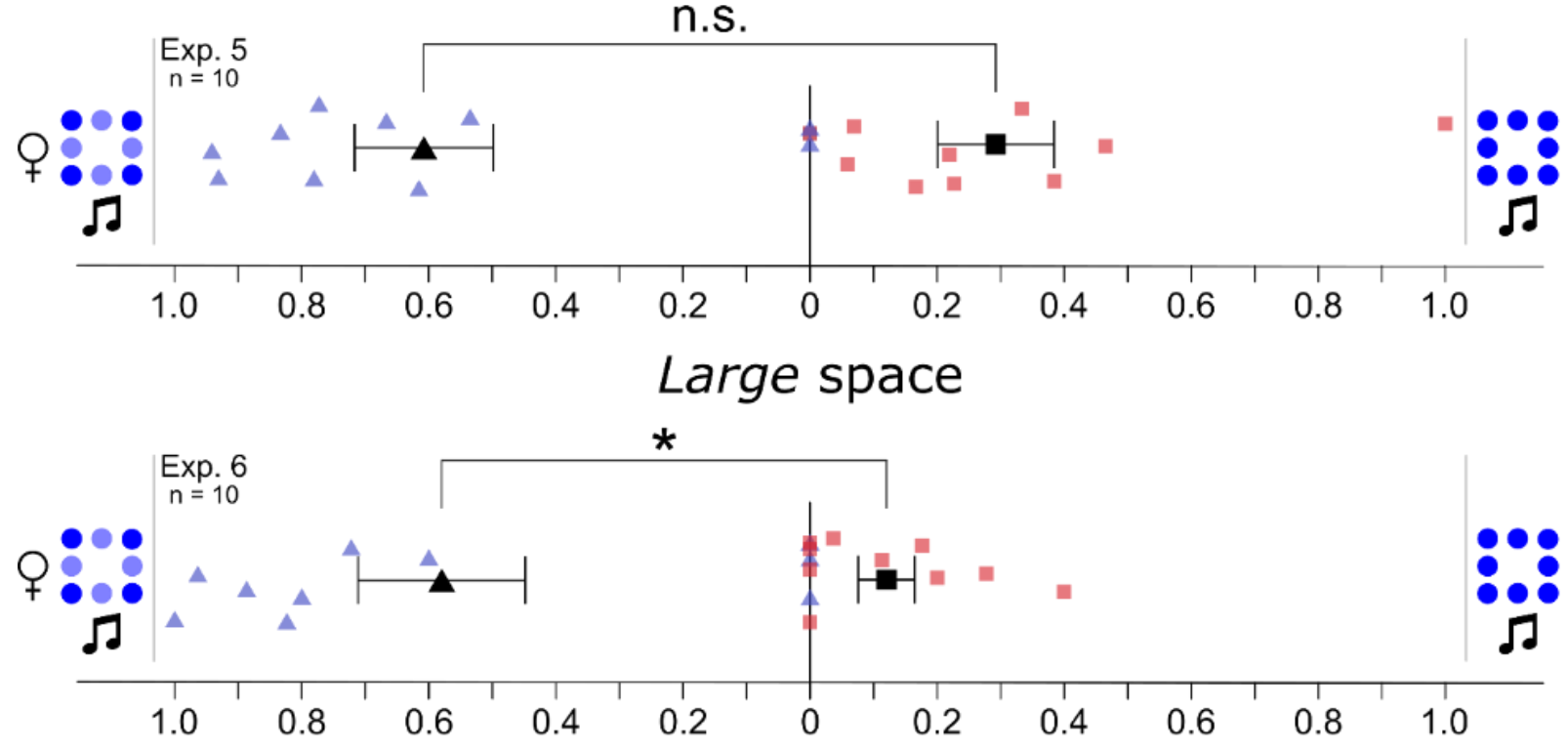

Proportion of total alightings by males on test stimuli

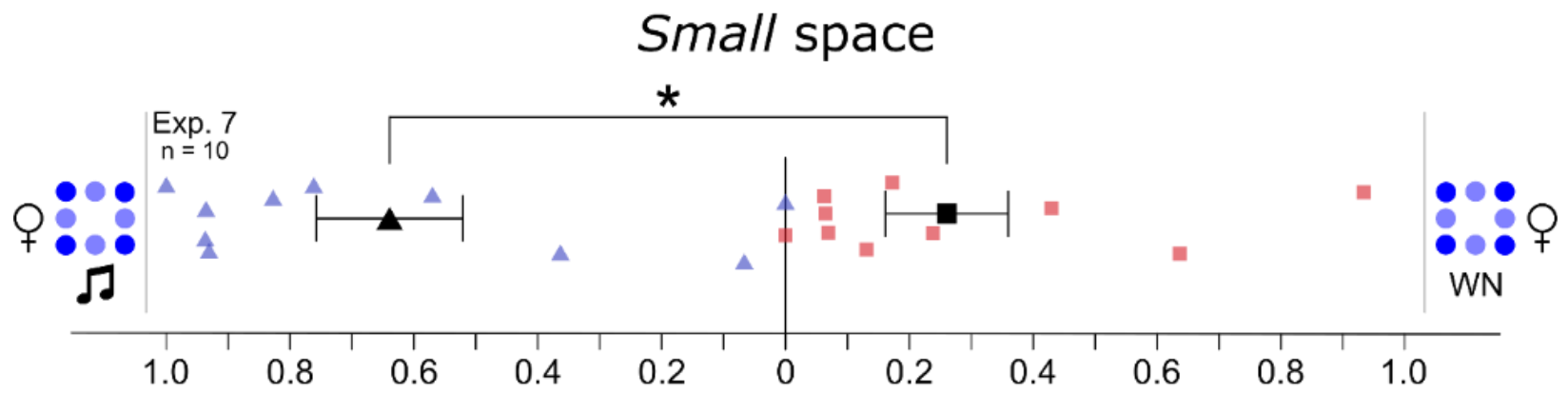

Small space

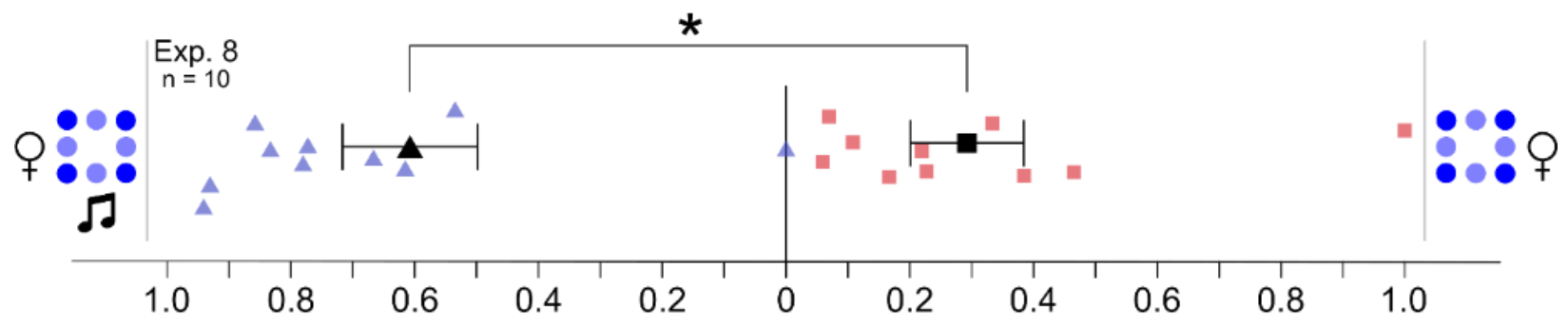




\section{Figure 4. Space-dependent effects of visual and acoustic signals tested in combination on}

738 alighting responses of 2- to 7-day-old male Aedes aegypti. The number of blue dots represents

739 the number of blue LEDs contained within each of two LED arrays (Fig. 1B), one of which was

740 emitting light flashes (depicted as a mixture of light- and dark-blue dots) at the 665-Hz wingbeat

741 frequency of female Ae. aegypti, and the other array was emitting constant light (depicted as

742 uniformly dark-blue dots). Musical notes and WN (white noise) indicate concurrent broadcast of

743 female wingbeat sound $(665 \mathrm{~Hz})$ and white noise, respectively. Light blue triangles and light red

744 squares show the data of individual replicates and black symbols the mean $( \pm \mathrm{SE})$. Experiments

745 were conducted in a mesh cage [Small space (Fig. 1A,B); Exps. 5, 7, 8] or within a bioassay

746 room [Large space (Fig. 1D,E); Exp. 6]. For each experiment, an asterisk indicates a significant

747 preference (binary logistic regression model; $\mathrm{p}<0.05 ; \mathrm{n}$. s. = not significant). 
Small space

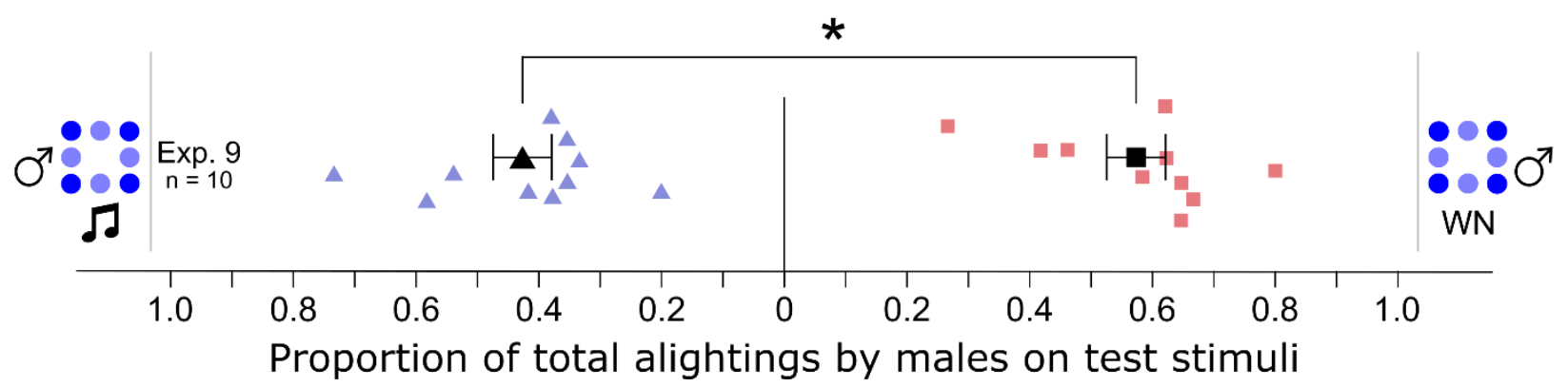

763 Figure 5. Effect of visual and acoustic signals tested in combination on the alighting

764 responses of 2- to 7-day-old male Aedes aegypti. The number of blue dots represent the

765 number of blue LEDs contained within each of two LED arrays (Fig. 1), with LEDs flashing

766 light at the 715-Hz wingbeat frequency of males. The musical note and WN (white noise)

767 indicate concurrent broadcast of male wingbeat sound $(715 \mathrm{~Hz})$ and white noise, respectively.

768 Light blue triangles and light red squares show the data of individual replicates and black

769 symbols the mean $( \pm \mathrm{SE})$. The asterisk indicates a significant preference for WN (binary logistic

770 regression model; $\mathrm{p}<0.05)$. 


\section{Large space}

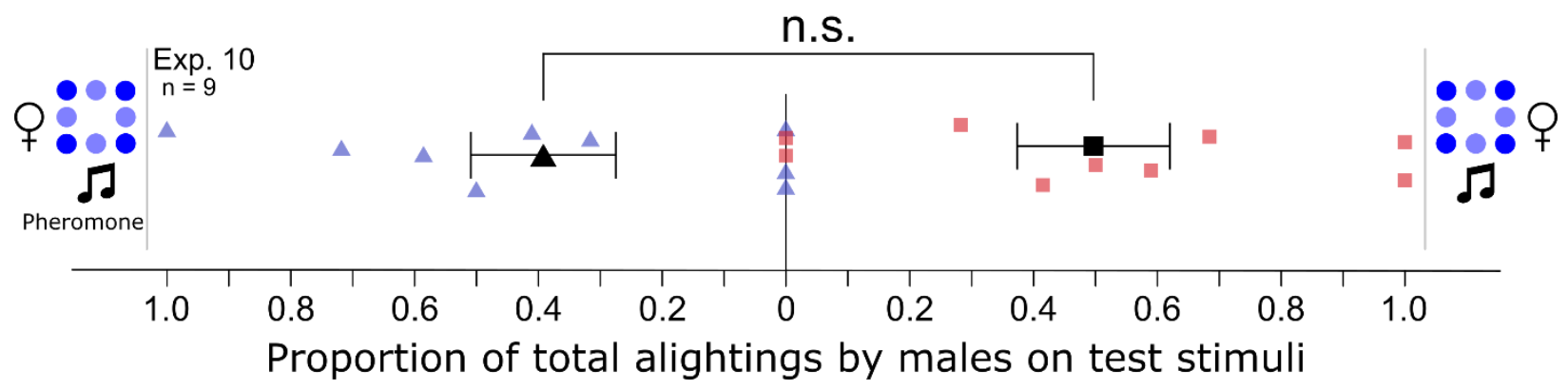

783 Figure 6. Effect of ketoisophorone on the alighting responses of 2- to 7- day old male Aedes

784 aegypti. The number of blue dots represents the number of blue LEDs contained within each of

785 two LED arrays (Fig. 1), with LEDs flashing light at the 665-Hz wingbeat frequency of female

786 Ae. aegypti. Musical notes indicate broadcast of female wingbeat sound $(665 \mathrm{~Hz})$ and

787 'Pheromone' indicates the presence of synthetic ketoisophorone (Fig. 1 I), a female produced

788 pheromone component. Light blue triangles and light red squares show the data of individual

789 replicates and black symbols the mean $( \pm \mathrm{SE})$. There was no preference for either set of test

790 stimuli (binary logistic regression model; $\mathrm{p}>0.05 ; \mathrm{n} . \mathrm{s} .=$ not significant). 


\section{Small space}

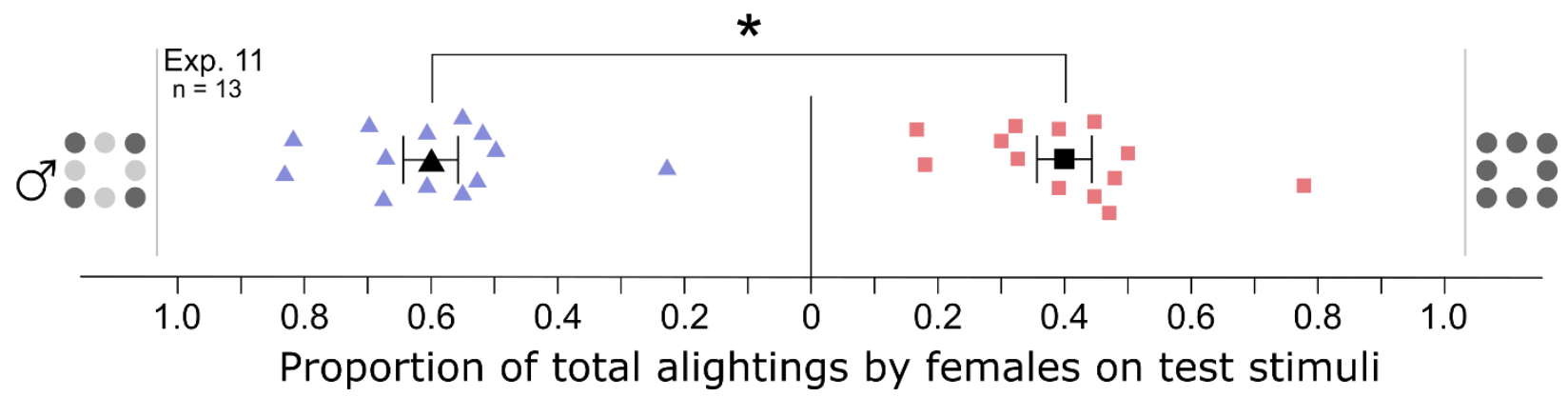

\section{Figure 7. Effect of visual signals on alighting responses of 5- to 10-day-old virgin female}

801 Aedes aegypti. The numbers of grey dots represent the number of white LEDs contained within

802 each of two LED arrays (Fig. 1), one of which was emitting light flashes (depicted as a mixture

803 of light- and dark-grey dots) at the 715-Hz wingbeat frequency of male Ae. aegypti, and the other

804 LED array was emitting constant light (depicted as uniformly dark-grey dots). The asterisk

805 indicates a significant preference for the $715 \mathrm{~Hz}$ LEDs (binary logistic regression model; $\mathrm{p}<$

$806 \quad 0.05)$. 